\title{
Los archivos monásticos medievales de las cistercienses leonesas
}

\section{The medieval monastic archives of the Cistercian female convents of León}

\author{
Gregoria Cavero Domínguez \\ Universidad de León \\ gcavd@unileon.es \\ https://orcid.org/0000-0003-3724-2356
}

\section{Resumen}

Los archivos de los seis monasterios cistercienses femeninos con que contó la actual provincia de León en la época medieval son la base del presente trabajo. No todos ellos han conservado sus ricos archivos pero sí la mayoría: la mayor parte no desaparecieron con la desamortización, con lo que las monjas los conservaron adecuadamente. Además de los archivos monásticos como tales, algunos cenobios han conservado los archivos nobiliarios de los linajes fundadores. Todo ello da a estos fondos documentales un gran significado y un especial interés; $y$ ello explica que haya fondos muy anteriores al Císter, desde el siglo X. El ejemplo más notable es el del monasterio de Santa María de Otero de las Dueñas.

Palabras clave: Archivos, monasterios, Císter, femenino.

\section{Abstract}

The archives of the six female Cistercian monasteries existing in the present province of León during the Middles Ages are the basis for this work. Not all of the communities have preserved their rich archives but most of them have. The majority of the collections did not disappear after Mendizábal disentailment; so the nuns conserved them properly. Besides the monastic archives as such, some of the nunneries have preserved the archives of the noble lineages that founded them. All of this provides a singular meaning and interest to these documentation collections; and that explains that there are files from a much more previous date than the foundation of the Cistercian Order -from the 10th century. The most notable case is that of the monastery of Santa María de Otero de las Dueñas.

Key words: Archives, monasteries, Cister, female. 


\section{Introducción}

La gran difusión del Císter en el Reino de León, en general, y en el actual marco provincial leonés, en particular, es nuestro punto de partida para un análisis de los fondos documentales de los monasterios cistercienses leoneses medievales. Contamos con seis cenobios, uno de los cuáles, el de Santa María de Gúa, desapareció del entorno leonés para asentarse en tierras asturianas; ${ }^{1}$ la ausencia de un archivo medieval hace que sea la única excepción del panorama que voy a analizar.

La riqueza y el interés por los cinco fondos documentales medievales restantes ha propiciado su publicación, en su mayor parte en la colección de Fuentes y Estudios de Historia Leonesa. ${ }^{2}$ San Miguel de las Dueñas y Villabuena, cuyos monasterios se unificaron en el primero han sido publicados por la Universidad de León; el primero, como catálogo. $^{3}$

Como característica debemos señalar que una parte muy significativa de los fondos documentales permanecen en los

1 YÁÑEZ NEIRA, D. "El monasterio cisterciense de las Huelgas de Avilés". Boletín del Instituto de Estudios Asturianos, 1969, n. 68, pp. 341-372; PÉREZ ÁLVAREZ, M. J. "Presencia y desarrollo del dominio monacal de las monjas bernardas de Avilés en el Valle de Laciana". En Claustros Leoneses olvidados. Aportaciones al monacato femenino. León, 1996, pp. 125-133. Podemos interpretar que el monasterio inicialmente estuvo en el lugar de Santibáñez y luego pasó a Gúa: es decir, que estuvo en las vertientes leonesa y asturiana del puerto de Somiedo. En el siglo XVI el monasterio se trasladó a Avilés, pero mantuvo el coto de Gúa, y terminó en la desamortización. CAVERO DOMíNGUEZ, G. EI esplendor del Císter en León, siglos XII-XIII. León, 2007, pp. 80-81. monasterios correspondientes, dado que la desamortización afectó menos a los cenobios femeninos. Ello no significa que no les afectara. Quizás el caso más sonoro sea el de Santa María de Otero de las Dueñas, lo que significó una dispersión brutal de la documentación. Acabó en distintos archivos, nacionales y locales, hasta el punto de que una parte se halla todavía en paradero desconocido.

De los otros cenobios, Gradefes tiene alguna documentación también en el Histórico Nacional, al igual que San Miguel de las Dueñas. Por su parte, el de Villabuena quedó totalmente integrado en San Miguel de las Dueñas, al sumarse ambas comunidades; lo que no impidió también la dispersión (sistema de encomienda: archivo ducal de Medina Sidonia, Casa de Alba).

Otra reflexión se deriva de la desaparición de comunidades femeninas y la recogida de sus archivos en aquellos monasterios con los que han tenido dependencia o relación. Esto ha ocurrido en época medieval, moderna y actual. En Gradefes se encuentra parte de la documentación, de época moderna, de los

2 CASADO lOBATO, M. C. Colección diplomática del monasterio de Carrizo (León), I: Introducción, documentos de los años 969-1260; II: Documentos de los años 1260-1299 e Índices. León, 1983. BURÓN CASTRO, Taurino. Colección documental del monasterio de Gradefes; I (1054-1299), León 1998; y II (1300-1899). León, 2000. FERNÁNDEZ FLÓREZ, J. A. Y HERRERO DE LA FUENTE, M. Colección documental del monasterio de Santa María de Otero de las Dueñas (854-1108); I (854-1108) León, 1999; y II (1109-1299) e Índices. León, 2005.

${ }^{3}$ CAVERO DOMíngueZ, G. Catálogo del monasterio de San Miguel de las Dueñas. León: Universidad de León, 1994. MARTín LÓPEZ, M. E. y CAVERO DOMÍNGUEZ, G. Colección documental del monasterio de San Guillermo de Villabuena (11721527). León: Universidad de León, 2017. 
anteriores monasterios de Otero de las Dueñas y de las Huelgas de Avilés, heredero de Santa María de Gúa. ${ }^{4}$ En San Miguel de las Dueñas, el monasterio de Villabuena $y$, recientemente, el de las cistercienses de Alcalá de Henares.

\section{Archivo de Santa María de Carrizo}

Dice C. Casado que el Archivo de Santa María de Carrizo comenzó a ordenarse a comienzos del siglo XVII y se realizó, concretamente, entre 1611 y 1620.5 Curiosamente, para poner orden, las monjas contaron con el licenciado Jerónimo de Robles, abogado, que además realizó un tumbo conocido como Tumbo Antiguo. Se realizó por interés abacial $y$ por necesidad de orden; y, por ello, se cuenta con una infraestructura adecuada, con el fin de primar especialmente la claridad y la facilidad de consulta: por legajos y en cajones, como señala su organizador, Robles. Para ello, cada documento fue numerado, en el reverso, con un número y con el legajo y cajón correspondientes; y a ello se añadía el lugar, tema y persona.

El mobiliario correspondiente ya se había hecho necesario en el siglo XVI, y ahora era imprescindible; la cajonería, posiblemente mandada hacer por la abadesa Isabel Osorio, ${ }^{6}$ fabricada inicialmente en el siglo XVI, fue renovándose y ampliándose en las centurias siguientes. Las monjas entendieron que un archivo bien organizado era la base para un control del patrimonio adecuado $y$, especialmente, para obtener las rentas pertinentes que les permitieran sobrevivir.

4 “...la comunidad de Gradefes acogió a finales del siglo XIX a monjas de otros dos monasterios, que habían sido desposeídas de sus moradoras como consecuencia de los avatares revolucionarios del año 1868. Ambos eran cistercienses y radicados en la diócesis de Oviedo, aunque uno procedía de la provincia de León. Éstos no incorporaron íntegros sus respectivos fondos documentales en el hospitalario de Gradefes, como hubiera sido lo correcto; sin embargo queda suficiente constancia a través de algunos pergaminos, papeles sueltos y libros de los mismos que, aunque muy disminuidos
A esta ordenación del siglo XVII se sumó la confección de dos tumbos, programados para anotar cuanto fuera de interés. El uno se conoce como Tumbo Antiguo; el otro, como Tumbo Nuevo. El primero, de la misma época, siglo XVII, y posiblemente del licenciado Robles. Al segundo, para diferenciarlo del primero, se le da el nombre de Tumbo Nuevo y pertenece al siglo XVIII.

Se habla igualmente de escrituras en pergamino y papel, cómo deben registrarse en el Tumbo siguiendo un orden cronológico. Han de tenerse en cuenta aquellas escrituras que no hablan directamente del monasterio, así como explicar la procedencia de algunas de ellas.

C. Casado publicó, en dos volúmenes, la documentación de Carrizo, desde el siglo $X$ hasta 1300. Por lo tanto, la documentación de los siglos bajomedievales, bien ordenada en el monasterio, sigue sin una publicación total.

La documentación anterior a 1300 es fundamentalmente del siglo XIII; lo que se corresponde con la etapa inmediata a la fundación del monasterio (1176) por Estefanía Ramírez. Son, en total, 608 documentos; de los que 544 pertenecen al siglo XIII, mayoritariamente en pergamino, pero también algunos en papel. Son la documentación real; documentos relacionados con la orden cisterciense y otras, algunos documentos particulares $\mathrm{y}$, en su mayoría, la documentación generada por el monasterio: todo ello, muy relacionado con su patrimonio y la gestión que ello requería. La fundadora, Estefanía Ramírez, era hija de

y desperdigados de su primitivo origen y unidad, forman parte integral del actual archivo del monasterio y constituyen un testimonio de celo y afecto que por los mismos sintieron las religiosas que los transportaron hasta aquí. Son estos los monasterios de Santa María de Gúa o Bernardas de Avilés, y el de Santa María de Otero de las Dueñas". BURÓN. Gradefes, I, p. IX.

${ }^{5}$ CASADO. Carrizo, I, pp. XXI-XXIV.

${ }^{6}$ CAVERO. El esplendor del Císter, p. 250. 
Ramiro Fróilaz y nieta de Froila Dídaz y Estefanía Sánchez; y es precisamente este linaje el que marcó el poder económico de la fundadora, casada con Ponce de Minerva: ambos, protagonistas de varias fundaciones monásticas y muy ligados al Císter.

Desde el punto de vista geográfico, el archivo de Carrizo es totalmente leonés y abarca un ámbito bastante reducido entre el Páramo leonés y la cuenca hidrográfica del río Órbigo: desde los cursos del Luna y Omaña, que dan origen al Órbigo, hasta los afluentes del curso bajo, ya que se prolonga hacia las cuencas hidrográficas de los afluentes Eria, Jamuz, Duerna y Tuerto.

El monasterio fue fundado, como hemos mencionado, en 1176, y el documento fundacional se hallaba en el Archivo de la Catedral de Astorga, sin duda por el sometimiento del monasterio cisterciense al ordinario asturicense. Con motivo de la celebración del VIII centenario del monasterio, dicho documento fundacional fue devuelto al archivo monástico, donde se custodia desde entonces. ${ }^{7}$

Cuando la condesa Estefanía Ramírez fundó el monasterio de Santa María de Carrizo, le entregó las villas de Carrizo, San Pedro del Páramo, Grulleros y Argavallones y distintas heredades en diversos lugares, señalando que procedían de su patrimonio. Para entonces la condesa Estefanía estaba viuda y protegiendo los intereses de su hija María; por lo que advierte que la donación de Carrizo es para fundar una abadía femenina cisterciense; pero si el Císter no lo aceptase, que la condesa María, su hija "sit potestate at prouidentia

${ }^{7}$ A ello se refiere también C. Casado (Carrizo, I, p. 43, doc. 38), al registrar el documento: "Este pergamino, que estaba últimamente en el Archivo de la Catedral de Astorga, fue entregado en 1980 al AMC".

${ }^{8}$ CAVERO, El esplendor del Císter, p. 95.

9 CAVERO DOMínguEZ, G. "Las condesas Estefanía Ramírez y su hija María Ponce: estrategias familiares femeninas". En Femina. Mujeres en la faciendi ibi abbatiam sub quocumque ordine Deo seruientium sibi placuerit" ${ }^{8}$. María sería la abadesa y controlaría la fundación junto a su madre. ${ }^{9}$

Con la fundación, Estefanía dejaba en Carrizo algunos diplomas de su linaje relacionados con el patrimonio que forjaba para Carrizo; pero realmente muy pocos eran anteriores al siglo XII: en total, tres documentos, uno del siglo $X$ y dos del siglo XI. Es decir, que, con ella, no pasó a Carrizo el archivo nobiliario del linaje; ello se debió fundamentalmente a que, por una parte, tenía tres hijos; ypor otra, a la dispersión documental en base a la colaboración con distintas fundaciones monásticas, en León y Castilla, del Císter y fuera de él. Solamente una treintena de documentos de la Colección de Carrizo, pertenecientes al siglo XII, son anteriores a la fundación monástica. C. Casado comenta al respecto: "los documentos con referencia expresa al monasterio de Carrizo son poco más de la quinta parte de la colección" ${ }^{10}$.

Ya la editora de la colección pone de manifiesto cómo en el archivo carricense se hallaba una "gran cantidad de escrituras" de Gonzalo Morán y su mujer, Elvira Rodríguez, dando la explicación de que "una hija suya, María Gonzálvez, fue abadesa en este monasterio, al que deja una importante donación de heredades. Aparece en esta documentación como abadesa entre los años 1289 a 1297"11. Ciertamente esta familia Morán, que estaba emparentada también con los Fróilaz, tiene en el archivo de Carrizo su

Historia, coordinado por Cristina de la Rosa Cubo et al. Valladolid, 2015, pp. 49-70.

10 CASADO, Carrizo, I, p. XXXIII. La editora hace una pequeña clasificación cronológica, en tres bloques: a) Documentos del siglo XII. b) Documentos del siglo XIII: primera mitad. c) Documentos del siglo XIII: segunda mitad, con una descripción general del contenido y tipología de los citados documentos.

${ }^{11}$ CASADO. Carrizo, I, pp. XXII-XXIII. 
archivo familiar. En su día llamó la atención de investigadores como Gautier Dalché ${ }^{12}$.

Canal Sánchez-Pagín ${ }^{13}$, que había estudiado la Casa de Haro, también dedicó un pequeño estudio a la documentación de Carrizo en la Colección Salazar de la Real Academia de la Historia; y, más recientemente, desde la Universidad Carlos III, se planteó un proyecto para la catalogación del fondo en papel.

Santa María de Carrizo se ubica en la cuenca media del río Órbigo y se encontró siempre en las disputas desatadas por el control del agua y sus presas. En dichos enfrentamientos estaba también la villa de Santa Marina del Rey perteneciente a la Iglesia de Astorga; Benavides, cabeza de la casa condal de los Quiñones, condes de Luna; y finalmente la orden militar de San Juan, asentada en Puente de Órbigo. Como consecuencia de tantas disputas entre las instituciones citadas, el monasterio conserva importante documentación al respecto.

\section{Archivo de Otero de las Dueñas}

Se trata de un fondo espectacular (que había suscitado ya mucho interés ${ }^{14}$ ) procedente de diversos "fondos", que fue publicado en su forma más completa por J. A. Fernández Flórez y Marta Herrero de la Fuente. En sí, fue un fondo muy dispersado, que apareció en dos volúmenes y que alberga toda la documentación nobiliaria de la fundadora del monasterio de Otero de las Dueñas, cosa que no hizo hasta 1230; la documentación

12 GAUTIER DALCHÉ, J. "Noblesse, terre et argent au XIII siècle: l'exemple de la famille léonaise des Moran". En Histoire et Societé. Mélanges offerts a Georges Duby. Université de Provence, Aix-enProvence, 1992, pp. 97-105. Véase también DA COSTA C. NASCIMENTO, M. F. “Los Morán: un linaje nobiliario en León (siglo XIII)”. Astorica, 1990, n. 9, pp. $75-142$; y 1991 , n. 10, pp. 11-64.

13 CANAL SÁNCHEZ-PAGíN, J. M. "Documentos del monasterio de Carrizo de la Ribera (León) en la Colección Salazar de la Real Academia de la Historia". Archivos Leoneses, 1978, n. 64, pp. 381403. aportada parte del siglo X. Como dice Alfonso Prieto, "por las venas de doña María Núñez corría la sangre de dos personajes que crearon, a principios del siglo XI, dos señoríos: Froila Muñoz y Pedro Flaínez; el primero, procedente de Asturias y hacendado en el valle de Lena, fue acumulando propiedades alrededor de la villa de Viñayo, donde más tarde se erigiría el monasterio cisterciense de Santa María de Otero. El segundo haría lo mismo a orillas del Esla"15. Ambos condes eran antepasados de María Núñez y de ellos es una parte muy significativa de este archivo monástico, que alberga un archivo nobiliario de significativo alcance. Estos documentos nobiliarios proceden de "dos archivos nobiliarios, los reunidos y organizados por los ascendientes y descendientes de los que quizá podríamos considerar portaestandartes 0 figuras más representativas de sus respectivas familias", los condes citados, Fruela Muñoz y Pedro Flaínez, ${ }^{16}$ y en las comarcas de los ríos Esla y Luna. Así, por ejemplo, se hablaría de unos 500 documentos, de entre 946 y 1245, pertenecientes a los Flaínez. "En su gran mayoría son pergaminos originales y en un alto porcentaje se trata de documentos relativos a una larga serie de miembros de la parentela Flaínez, que dominaron la ciudad de León y Las Somozas desde finales del siglo X: en particular brillan el conde Flaín Muñoz, su hijo Pedro Flaínez, sus nietos Fáfila y Diego Pérez, y María Froilaz que fue esposa de este último e hija de Froila Muñoz... Todos estos magnates cubren el período 985-1075"17.

\footnotetext{
${ }^{14}$ A título de ejemplo, véase RODRÍGUEZ, Raimundo. Catálogo de documentos del monasterio de Santa María de Otero de las Dueñas. León, 1949.

15 PRIETO PRIETO, A. "Documentos referentes al orden judicial del monasterio de Otero de las Dueñas". Anuario de Historia del Derecho Español, 1974, n. 44, p. 620. Los recogen también FERNÁNDEZ y HERRERO. Otero, I, p. 21.

${ }^{16}$ FERNÁNDEZ y HERRERO. Otero, I, p. 22.

${ }^{17}$ Ibíd. II, p. 11
} 
a) El primer volumen, entre 854-1108, recoge 320 documentos, que proceden de cuatro fondos diferentes:

-Fondo Otero, propiamente dicho, en el Archivo Histórico Diocesano de León.

-Fondo Raimundo Rodríguez, en el Archivo Catedral de León.

-Fondo Miguel Bravo, también en el Archivo Histórico Diocesano de León.

-Fondo Torbado, en paradero desconocido.

Como bien explican sus editores, "la inmensa mayoría de la documentación altomedieval está relacionada con personas o instituciones eclesiásticas $\mathrm{y}$, desde luego, toda ella nos ha llegado a través de dichas instituciones" ${ }^{18}$. El primer documento es de Ordoño I, si bien no es original.

Cuantos se han acercado a la documentación de Otero coinciden en que el ámbito territorial al que se refiere la citada documentación se centra, prioritariamente, en las cuencas del Órbigo, del Esla y del Porma, con Viñayo y Valdoré como lugares que concentraron la mayor agrupación de propiedades; más alejadas, la cuenca de Lena y la del Sil; y extensible el ámbito geográfico, ocasionalmente, hasta la Tierra de Campos y zonas tan alejadas como Nájera.

Ciertamente sobre estas propiedades del alto curso del Órbigo, que anteriormente se forma en la unión de los cauces de los ríos Luna y Omaña, se fundaría el monasterio de María Núñez, en Otero, desde entonces llamado de las Dueñas. ${ }^{19}$ Aguas abajo se halla Carrizo, donde ella había estado anteriormente, que compartiría la dependencia cisterciense; y del otro lado, Gradefes, igualmente bernardo, donde también estuvo María Núñez, sobre la cuenca del Esla. Aguas abajo de Gradefes, cuando el Porma vierte sus aguas al Esla, se

18 Ibíd. I, p. 22.

19 "La villa de Otero se halla sobre la convergencia de dos pequeños arroyos que vierten sus aguas en el río Luna, el Torre y el Piedrasecha, cuyos valles se asienta el masculino y también cisterciense monasterio de Sandoval. Parece claro que la relación del escenario geográfico de la documentación nobiliaria altomedieval de María Núñez está en relación directa con tres fundaciones cistercienses asentadas en dichas cuencas fluviales, todas ellas anteriores a la fundación de Otero.

La citada documentación, como afirman sus editores, es mayoritariamente original, en su mayoría escrita en visigótica, tanto cursiva como redonda, que en los comienzos del siglo XII apuntan a la carolina. Un alto porcentaje son cartas de venta y el conjunto documental; y ofrece "47 documentos anteriores al año 1000 , de los cuales solamente tres son copias... en pergaminos independientes, es decir, sin que nos hayan llegado a través de cartularios elaborados en fechas mucho más tardías" 20

b) El segundo, con cronología 1109-1300, recoge 485 documentos.

Es precisamente en el segundo volumen donde se integra ya toda la documentación correspondiente a los siglos XII y XIII, antecedentes de la fundación de Santa María de Otero de las Dueñas, cuando María Núñez era ya anciana. Desde 1230 hasta 1300, se contabilizan 349 documentos; con lo que queda claro el gran desarrollo scriptorio y de control patrimonial que se llevaba a cabo especialmente en y después de la fundación monástica sobre las otrora bases patrimoniales de los Flaínez en los que se ubicaría el monasterio cisterciense.

Esta documentación es de un ámbito geográfico circunscrito prioritariamente a la cuenca del río Órbigo; documentación, original en su mayor parte. Hasta el $95 \%$ son

hallan separados por alturas superiores a $1.000 \mathrm{~m} . "$ CAVERO. El esplendor del Císter, p. 32.

${ }^{20}$ FERNÁNDEZ y HERRERO. Otero, I, p. 28. 
documentos originales, casi todos en pergamino, pero introduciendo ya el papel. ${ }^{21}$

Hay una gran actividad en los años inmediatamente posteriores a la fundación monástica, especialmente desde 1230 hasta la muerte de María Núñez, en 1255. La problemática se suscitó en torno a propiedades de María Núñez, por compromisos familiares y por relaciones con otros monasterios, tanto cistercienses (Sandoval, La Espina, Carrizo ${ }^{22}$ ) como de otras órdenes; por ejemplo, con Santa María de Carbajal y San Pedro de las Dueñas: ambos, femeninos y benedictinos; ${ }^{23}$ y con la canónica isidoriana de León. ${ }^{24}$ En 1240, María Núñez de Guzmán, intitulándose condesa, da "a la Orden de Cistel Santa Maria de Otero, para façer y monasterio de dueñas de la Orden de Çistel", enumerando las heredades y vasallos "con el señorio, mero, misto inperio e jurissdiccion ziuil e creminal, e con los derechos todos que io auia e e auer", que configuran el patrimonio monástico, entre los que sobresale el lugar de Otero. ${ }^{25}$ Para entonces la comunidad monástica ya estaba funcionando, porque María Núñez dice: "Suma de los basallos duçientos e sesenta e nueue, que da aqueste monasterio; de las quales dichas heredades e destas eglesias e de estos vasallos e de señorio e de quantos derechos e en tierra de Leon, de todo me desapodero e dolo a la Orden de Çistel, assi que la abbadesa de Santa Maria, que es aora doña Maria, doña Theressa Alfonsso, del conuento e las demas que vernan despues della, fagan con sus fixas segun que es la abbadesa de Burgos sobre las suas"26. El modelo de referencia lo constituía la abadesa

\footnotetext{
${ }^{21}$ Ibíd. II, pp. 27-29

22 Ibíd. Documentos 502 y 503.

${ }^{23}$ Ibíd. Doc. 465.

24 Ibíd. Docs. 504 y 522.

25 Ibíd. Doc. 532, p. 310.

${ }^{26}$ Ibíd. Doc. 532, p. 311.
}

de las Huelgas de Burgos. No en vano María Núñez era hija de la reina Urraca López.

Hace unos años, G. Baury ${ }^{27}$ analizaba los inicios de la fundación de Otero y señalaba, en el resumen de su artículo, lo siguiente:

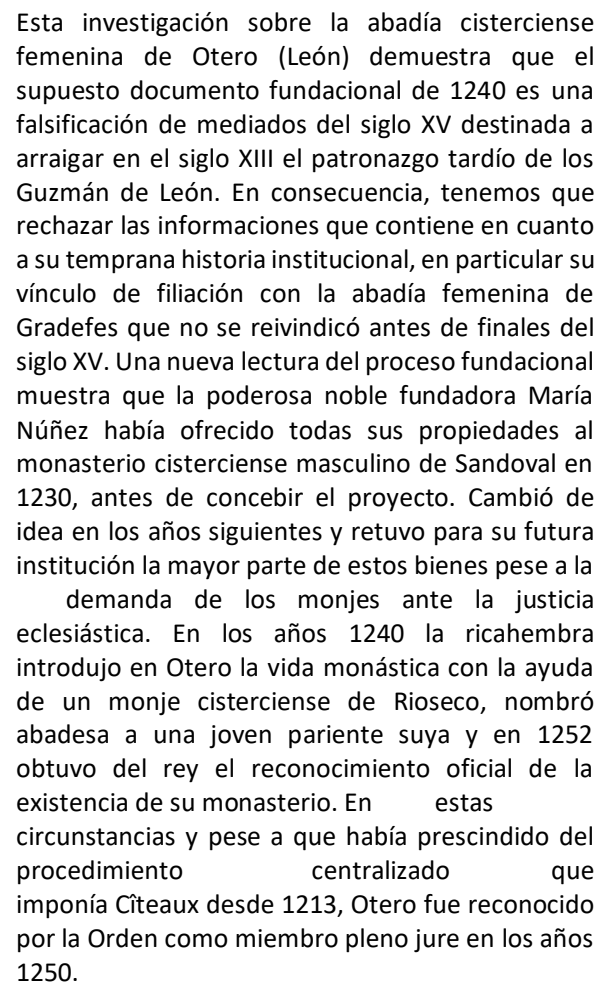

Ciertamente el documento fundacional no estaba exento de dudas, con decisivas interpolaciones, como el citado autor demostró, pero lo más significativo, en nuestro estudio, es que la fundación de Otero constituía el lugar donde confluirían todas las escrituras acumuladas durante siglos por los ascendientes de María Núñez, hija de la reina Urraca e intitulada condesa. El archivo monástico de Otero albergaría así los dos archivos nobiliarios que sus ascendientes habían generado. En este caso sí que podríamos afirmar que se constituía en memoria del linaje.

${ }^{27}$ Sobre esta fundación, y con un minucioso análisis del documento fundacional de 1240, remitimos al exhaustivo trabajo de BAURY, Ghislain. "Fundar una abadía cisterciense femenina a mediados del siglo XIII. En torno a los inicios de Otero (1230-1452)". Estudios Humanísticos. Historia, 2014, n. 13, pp. 934. 
Desde 1300 en adelante el fondo de Otero no ha sido editado en su conjunto, ni estudiado. Su dispersión a raíz de la desamortización, ha dejado dos puntos fundamentales de ubicación de la documentación bajomedieval $y$, sobre todo, moderna: por una parte, el Archivo Histórico Nacional; por otra el Archivo Histórico Diocesano de León. Algunos documentos se hallan también en el fondo del monasterio de Santa María de Gradefes, por la otrora dependencia de Otero, o dispersos en manos de particulares. Incluso un Libro Becerro se halla en el Archivo del monasterio palentino de San Isidro de Dueñas ${ }^{28}$.

\section{Archivo de Gradefes}

Depositado durante algún tiempo fuera del monasterio -entre otros lugares, en el Archivo Histórico Diocesano de León-, el fondo documental de Santa María de Gradefes, actualmente en el propio monasterio, había sido de interés en distintas épocas y situaciones. En primer lugar, por necesidades internas, la propia comunidad monástica ya había hecho un catálogo en el siglo XVIII, con el fin de llevar el control patrimonial y los derechos de presentación. Pero igualmente ya había sido trabajado por el que fuera archivero de la Catedral de León Raimundo Rodríguez y por Aurelio Calvo ${ }^{29}$.

La publicación completa no llegaría hasta la edición de Taurino Burón, que recogió toda la documentación hasta el siglo XX: un total de 944 años, desde el año 1054. Lo hizo en dos volúmenes: el primero, hasta 1299, con transcripción completa; y el segundo, en

${ }^{28}$ FERNÁNDEZ y HERRERO. Otero, II, p. 15.

${ }^{29}$ CALVO, Aurelio. El monasterio de Gradefes. Apuntes para su historia y la de algunos otros cenobios y pueblos del concejo. León, 1936-1944.

30 "No obstante, de las notas dorsales se deduce claramente que la mayor parte de los pergaminos estaban agrupados por lugares y guardados en cajones, con toda seguridad, desde el siglo XVI. Otra buena parte se depositan en 'la zesta de palma', con su respectivo número; una menor en el 'cofrezillo del rey don Alfonso'". Sin duda que estas signaturas forma de catálogo documental, desde 1300 hasta 1899.

Como la mayor parte de los monasterios, Gradefes tenía un archivo monástico, en este caso ubicado en un armario, denominado "alhacena", dotado de "puertas y doce cajones", en los que se recogían tanto los "papeles" como los libros. Es evidente que en los cajones se ubicaría la documentación siguiendo una organización de lugares, con el fin de agilizar las consultas. ${ }^{30}$ Igualmente, para facilitar el control de las rentas y del patrimonio dispuso de Tumbos, al menos uno de finales del siglo $\mathrm{XVI}^{31} \mathrm{y}$ otro de principios del siglo XVII. ${ }^{32}$ Las monjas de Gradefes buscaron, para la realización de dichos tumbos, la colaboración de los cistercienses, primero de Sandoval, después de La Espina. El primero de ellos fue realizado por un monje de Sandoval, de nombre Mateo de la Vega, durante el abadiato de doña María de Quiñones Pimentel, y en opinión de T. Burón, cometió muchos y reiterados errores, especialmente en las datas cronológicas, al convertir la era al año. Fue Juan de Quintanilla, monje de la Espina, el que realizó otro tumbo en 1610, llamado Tumbo Nuevo o Tumbo Negro ${ }^{33}$.

Además de en el monasterio, hay documentación del cenobio de forma dispersa por otras instituciones y archivos. La que se encuentra en el Archivo Histórico Nacional procede, probablemente, de la época de la desamortización, y se halla con la de otros

domésticas servían para localizar a los documentos más importantes y más usuales. Éstas proceden de las notas dorsales y nos confirman que el archivo tenía una ordenación unitaria, aunque pudiera estar repartido en diferentes dependencias o habitáculos de arcas desde el siglo XVIII". BURÓN. Gradefes, I, p. XLIII.

${ }^{31}$ AHN, Clero. Libro Tumbo del Monasterio. Año 1594.

${ }^{32}$ CAVERO, El esplendor del Císter, p. 255.

${ }^{33}$ BURÓN. Gradefes, vol. I, p. XLVI. 
monasterios del entorno. ${ }^{34}$ En el Archivo de la Catedral de León hay algunas magníficas cartas de sumisión de la abadesa al obispo de León, del que dependía. ${ }^{35} \mathrm{Y}$ hay también documentación en el Archivo Histórico Diocesano de León. Como es habitual en todos los monasterios, los pleitos están recogidos en la Real Chancillería de Valladolid, en el Registro General del Sello (Archivo de Simancas), y, en general, en protocolos de distinta ubicación.

El archivo de Santa María de Gradefes se organizó reiteradamente a lo largo de los siglos, incluso desde la época misma de la fundación del monasterio en la segunda mitad del siglo XII, y posteriormente en el XIII. Pero realmente estas frecuentes organizaciones de archivo se hicieron muy necesarias desde el siglo XVI y a lo largo de las siguientes centurias. ${ }^{36}$ De la época medieval recoge 732 documentos, mayoritariamente anteriores a 1300 , tal como podemos ver en la edición de T. Burón, que seguimos.

34 "En el Archivo Histórico Nacional se archivan muchos documentos que se relacionan directa o indirectamente con los del monasterio, sobre todo en los más próximos de Eslonza y Sandoval. En el legajo citado de este Archivo, núm. 2600 de la Sección de Clero, existen una serie de contratos que forman secuencia con los del archivo del monasterio, pertenecientes a años de los siglos XVI al XIX. Son documentos sueltos que debieron de llegar allí por equivocación, como tantos que se recogían en los precipitados inventarios de la desamortización". Ibídem.

${ }^{35}$ Archivo de la Catedral de León, documentos 1519 y 1571; RUIZ ASENCIO, J. M. Colección documental de la Catedral de León, VIII (1230-1269). León, 1993, doc. 2158, p. 265, y doc. 2282, p. 491; y CAVERO, EI esplendor del Císter, pp. 162-164.

36 "En el siglo XVI se practican dos organizaciones del archivo: 1a. Una primera consistió en indizar los lugares citados en primer lugar del dorso del documento. Se utilizó un tipo de letra humanística uniforme. Aquí surge la duda de poder aclarar si la relación de estos lugares forma unidad con la

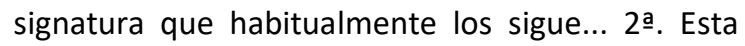
signatura es dudoso si formó uniformemente unidad con la enumeración anterior como se ha a) En el volumen I figuran 550 documentos, con una cronología situada entre 1054 y 1299, todos ellos elaborados en pergamino; la mayor parte corresponden al siglo XIII y se nota un aumento especialmente desde la fundación de Santa María de Gradefes en $1176 .{ }^{37}$ Además de la documentación del fondo monástico, Burón incluye documentos del Archivo Histórico Nacional ${ }^{38}$ y completa con documentación recogida en el Tumbo y hoy desaparecida.. De ellos, 103 son anteriores a la fundación del monasterio, en buena medida relacionados con los propios fundadores de Gradefes y con las propiedades que entregaron para la constitución patrimonial del cenobio cisterciense, mayoritariamente entre Tierra de Campos y La Ribera.

La documentación, que utiliza como soporte el pergamino ${ }^{39}$, es clasificada por su editor en tres tipologías documentales: documentos reales (69 diplomas), pontificios (3) y particulares.

descrito. Sigue un esquema único: 'Cajón... número...'” BURÓN. Gradefes, I, pp. XLIX-L.

${ }^{37}$ BURÓN (Gradefes, I, p. XIX) señala su distribución:

Siglo XI, 12 documentos

Siglo XII, 247 documentos

Siglo XIII, 291 documentos

${ }^{38}$ AHN, Sección Clero, carpeta 868. Se trata de cuatro documentos, bajo los números 164-165 y 186-187, como el mismo editor señala.

39 “El distinto grado de elaboración y la diferente procedencia de ovinos, caprinos y vacunos permite una clasificación sumaria en flexibles y rígidos, propiedades que no está relacionadas directamente con el grosor. Los capilares, los restos pilosos asi como el tono amarillento de algunos manifiestan que la mayor parte proceden de oveja o carnero, abarcando éstos desde el siglo XII al XIV, pudiéndose comprobar también la presencia de una parte menor de piel de ternero y de cabra, que se identifica por su color bastante más grisáceo, tacto más áspero y, en todos los caso por los folículos". BURÓN. Gradefes, I, p. XXI. 
Como señala el editor, "toda la documentación medieval emplea fórmulas diplomáticas convencionales, en cada uno de los períodos" 40 y destaca por el gran número de documentos de compraventa y donaciones. Abundan las cartas partidas por abc.

b) En el volumen II (1300-1899), siguiendo el criterio de la Colección de Fuentes y Estudios de Historia Leonesa, en que se incluye, se editan "en forma resumida los documentos datados a partir del año 1300, a no ser los que son considerados de importancia para el monasterio por alguna circunstancia histórica o jurídica" ${ }^{41}$.

La documentación bajomedieval, mucho más abundante en el siglo XIV y más escasa en el $X V$, ofrece cambios respecto a la de siglos anteriores. "A partir del siglo XIV, desde 1301 concretamente, se amplía o confirma el abanico de privilegios al monasterio para garantizar la exención de los nuevos impuestos: Pechos, pedidos, servicio, martiniega y yantar. Se reconoce nuevamente el derecho a los usos y costumbres y se concede un nuevo privilegio del impuesto sobre la aljama de los judíos de León, para que el mismo sirva de vestuario a las monjas del monasterio" ${ }^{\prime 2}$. Frente a la importante documentación regia, hay escasa documentación pontificia: dos bulas de Bonifacio VIII, datadas en 1300.

Es evidente que una buena parte de la documentación generada, tanto en el siglo XIII como en los dos finales de la época medieval, está en relación directa con la organización y defensa del patrimonio, con los sistemas de explotación directa e indirecta (distintos tipos de contratos) y las rentas generadas; pero,

\footnotetext{
${ }^{40}$ Ibíd., p. XXXIX.

${ }^{41}$ Ibíd., II, p. 9.b.

42 Ibíd., p. 11.

43 RUIZ ASENCIO, J. M. Colección documental de la catedral de León, III (986-1031). León, 1978, pp. 79101.
}

también con el poder señorial, los nobles benefactores que hacían donaciones y pedían ser enterrados en el cenobio, $y$, en algunos casos, con los descendientes de los fundadores, involucrados en la vida monástica.

\section{Archivo monástico de San Miguel de las Dueñas}

De los monasterios cistercienses leoneses señalados, este de San Miguel es el único que tuvo vida anterior, y posteriormente fue recuperado. En efecto, sabemos de su existencia en el siglo $X$ por un diploma de Vermudo II (ca. 998), que se encuentra en el fondo catedralicio legionense. ${ }^{43}$ Entre los bienes incautados por el monarca al noble Gonzálo Vermúdez y entregados a Sampiro, está el monasterio de Almázcara, que posteriormente pasaría al infantado leonés. ${ }^{44}$ De la mano de la infanta Sancha Raimúndez y con el apoyo de Alfonso VII, el monasterio de Almázcara retomaría la vida monástica en 1152, dentro de la gran confederación que aglutinaba el monasterio de San Salvador, después Santa María, de Carracedo, bajo signo benedictino. Este diploma de la infanta Sancha es una carta real que es el primer documento que se recoge en la catalogación del monasterio, si bien procedente de una copia del siglo XVI, en humanística. ${ }^{45}$

El archivo monástico de San Miguel de las Dueñas cuenta, en estos momentos, con tres fondos documentales: el propio, el de San Guillermo de Villabuena y el de las cistercienses de Alcalá de Henares. Son tres fondos independientes, que en el caso de los dos últimos llegaron con las propias comunidades religiosas que acabaron

\footnotetext{
44 Sobre este monasterio remitimos, en general, a CAVERO DOMÍNGUEZ, G., y GONZÁLEZ GARCÍA, M. A., El monasterio cisterciense de San Miguel de las Dueñas. León, 2000.
}

${ }^{45}$ CAVERO. El esplendor del Císter, pp. 78-79. 
integrándose en San Miguel. Al de San Guillermo de Villabuena nos referiremos posteriormente. El de Alcalá llegó hace unos años a San Miguel con las religiosas que procedentes de dicho monasterio, vinieron, iniciado el siglo XXI, a integrarse en el monasterio de Almázcara; y es en su mayor parte de época moderna, dado que fue fundado en el siglo XVII, sin que tenga un catálogo publicado.

Vamos a referirnos al archivo monástico de San Miguel, catalogado en $1994 .{ }^{46} \mathrm{Al}$ igual que hemos señalado para otros monasterios, el fondo de San Miguel se halla dividido, mayoritariamente, entre el propio monasterio y el Archivo Histórico Nacional, donde fue a parar, también como en otros casos, la documentación después de la desamortización decimonónica. La catalogación recoge ambos fondos, dado que, en su día, fueron el mismo. Se halla también documentación en otros fondos monásticos, especialmente cistercienses (Santa María de Carrizo, Carracedo) y bercianos (San Andrés de Espinareda); en los archivos catedralicios y diocesanos tanto de León como de Astorga; $y$, por supuesto en el Archivo General de Simancas; $y$, en algún caso, también en el Archivo Vaticano.

Si nos detenemos en la documentación medieval, solamente cuenta con 41 documentos. Entre ellos hay una copia posterior, en pergamino, del documento fundacional de la infanta doña Sancha, concediéndole el coto de Almázcara; y

${ }^{46}$ CAVERO DOMíngUEZ, G. Catálogo del monasterio de San Miguel de las Dueñas. León, 1994.

${ }^{47}$ Ibíd., docs. 176 y 194; el segundo, ya de 1500.

${ }^{48}$ Archivo del monasterio de San Miguel de las Dueñas: Tumbo en que se dará razón de todos los papeles e instrumentos de el archivo de este real monasterio de San Miguel de las Dueñas. Escriviólo y dispúsolo el Padre fray Thomás de Peralta, hijo de Osera y confesor en dicho monasterio.

${ }^{49}$ Archivo del monasterio de San Miguel de las Dueñas: Historia del Real Monasterio de Monjas algunos documentos pontificios, también escasos. ${ }^{47}$

Como puede deducirse, la documentación medieval se perdió en una buena parte, a veces por la inestabilidad de la comunidad monástica; y otras, por la negligencia que, en parte, viene dada por la falta de control directo de las monjas sobre su patrimonio y administración.

Como complemento, contamos en el monasterio de Almázcara con un Tumbo del siglo XVII y una Historia monástica del XIX. En ambos casos, la autoría se debe a monjes cistercienses de procedencia gallega: el padre Peralta, ${ }^{48}$ en el caso del Tumbo; y fray Ambrosio Delgado, en el segundo. ${ }^{49}$

Deteniéndonos en la documentación de los siglos XII-XV, además de la carta real de la infanta Sancha, ya señalada, el resto de la documentación regia está constituida por una confirmación de privilegios de Pedo I, en que se recogen las de otros monarcas anteriores desde Fernando III, en 1235, hasta Alfonso XI, en 1334; y es precisamente después confirmado también por Juan I, en 1379. Fuera de esto hay una carta de defensa de Juan I al monasterio en contra del duque de Benavente.

El resto son mayoritariamente documentos relacionados con el patrimonio, especialmente cartas de foro $y$ subaforamiento $(52,7 \%)$, censos, cartas de donación, apeos o documentos de régimen interno. Hay, sin embargo, un documento de especial interés, cuyo original se ha perdido:

Cistercienses de la Congregación de N. P. S. Bernardo, de San Miguel de las Dueñas, por el P. Fr. Ambrosio Delgado, monge de la misma orden, confesor cura del dicho monasterio parroquia. En este caso, el padre Delgado ya había dejado su monasterio, por la exclaustración; y, además de confesor, señala ser cura párroco, puesto que la iglesia monástica de San Miguel de las Dueñas era la parroquial del citado lugar, nacido con el monasterio. 
"Fuero de San Miguel. En este año -era 1254la abadesa doña Elvira y el convento aforan a ocho labradores, a sus mujeres e hijos, la heredad de Santa Cecilia, para que la cultiven. Ha de pagar cada uno de renta: dos sueldos, dos panes de trigo, una pixota, una hemina de cebada, media cuarta de vino, doce dias de servicio, la cuarta de lo que cogiesen, ademas de las ofrendas, diezmos y primicias de la yglesia de San Miguel..." ${ }^{50}$. Este fuero agrario es de gran importancia para el asentamiento de población entorno al monasterio, en este caso procedente de la zona de Laciana, ${ }^{51}$ y aparece recogido tanto en el Tumbo, que señala está duplicado, como en la Historia del monasterio.

\section{Archivo de San Guillermo de Villabuena}

Como ya se ha indicado, el archivo de San Guillermo de Villanueva se encuentra en el monasterio de San Miguel de las Dueñas, por la fusión de ambos monasterios, femeninos y cistercienses, en la primera mitad del siglo XVI, tras arruinarse la fábrica de San Guillermo por desbordamiento de las aguas del río Cúa, en cuyas proximidades se encontraba. Esa fue la causa final, pero realmente ambos monasterios ya estaban en un proceso de fusión, dado que las rentas del monasterio de San Miguel habían sido anexionadas al colegio de Alcalá, para su sostenimiento económico.

El archivo de San Guillermo de Villabuena tiene la ventaja de que forma un todo cerrado, puesto que su vida se establece entre 1229 y 1527. El monasterio era de fundación regia, por parte de la ex-reina leonesa Teresa de Portugal, primera mujer de Alfonso IX de León, con el apoyo del citado monarca, sin

${ }^{50}$ CAVERO. Catálogo de San Miguel, doc. 154, p. 56.

${ }^{51}$ CAVERO y GONZÁLEZ. San Miguel de las Dueñas.

52 YÁÑEZ NEIRA, D. "El monasterio de Villabuena, fundación de una santa reina". Archivos Leoneses, 1986, n. 40, pp. 79-80; CAVERO DOMÍNGUEZ, G. "Teresa de Portugal, reina de León". En Los Reyes de León, coordinado por Adolfo Alonso Ares, León, duda para proteger a las infantas Sancha y Dulce, fruto de su matrimonio. Se hizo sobre el cillero regio que se hallaba en el lugar de Villabuena $^{52}$ y bajo la dependencia del poderoso monasterio de Santa María de Carracedo. A ello añadimos que se realizó con la aquiescencia del pontífice Gregorio IX, en $1231 .{ }^{53}$

En su momento, el archivo villabonense fue catalogado y quedó inserto en el catálogo general de San Miguel (151 documentos), para posteriormente ser publicada su colección documental completa. Se trata de una colección que alberga 177 documentos. ${ }^{54}$

Un análisis del conjunto documental de lac Colección nos indica que procede, en su mayoría, del archivo originario del monasterio de San Guillermo. Publicamos íntegramente este fondo constituido por un centenar de documentos comprendidos entre los siglos XIII y XVI todos ellos confeccionados en pergamino de buena calidad. Una parte del fondo documental de San Guillermo fue sacado del archivo por diversos motivos, posiblemente casi todos relacionados con la administración y asuntos fiscales o procesales. Estos documentos desgajados de su archivo originario hoy se localizan en el Archivo Histórico Nacional, en la sección de Clero, seguramente procedentes de la desamortización. En segundo lugar, incluimos documentos que se encuentran en el Archivo de la Real Chancillería de Valladolid. Menos importante es la documentación recogida de los fondos catedralicios y diocesanos tanto de la Iglesia de Astorga, en la que se encontraba el monasterio, como de la de León.

La relación del monasterio de Villabuena con la nobleza de su entorno fue, sin duda, la

1994; e ID., "Teresa de Portugal y el monasterio de Villabuena (s. XIII)". Cistercium, 1997, n. 208, pp. 379-388.

${ }^{53}$ CAVERO, El esplendor del Císter, pp. 82-83.

${ }^{54}$ Véanse las referencias en la nota 2. 
causa de que alguna documentación, realmente importante para el cenobio, esté en el Archivo de los Duques de Alba, en Madrid, así como en el Archivo de los Duques de Medina Sidonia, en Sanlúcar de Barrameda. Los Osorio Villafranquinos, titulares del marquesado, entroncados matrimonialmente con la Casa de Alba, explican que el documento fundacional se encuentre en esta última, a pesar de que el documento dotacional es del XIII. ${ }^{55}$ La ruina económica de San Guillermo está muy relacionada con esta nobleza, cuyo palacio se ubicaba en una zona muy próxima al monasterio y de donde procedieron algunos de los encomenderos más poderosos de la Baja Edad Media. De hecho, en 1431 la abadesa y el convento de San Guillermo de Villabuena, manifestando gran penuria económica, entregaban a Pedro Álvarez Osorio, señor de Cabrera y Ribera, varios de los lugares dotacionales registrados en el documento otorgado por Alfonso IX ya señalado. Se esperaba del Osorio que los recuperase y que además pagase al monasterio anualmente una renta de 500 maravedís. Posiblemente el documento iría como aval de dicho acuerdo junto con buena parte de la hacienda villabonense, que pasaría a manos de los marqueses de Villafranca ${ }^{56}$. Una centuria más tarde el monasterio había desaparecido. Nunca recuperaron los bienes usurpados ni el documento regio. Por esta misma vía varios documentos de Villabuena fueron a parar al archivo de la casa ducal de Medinasidonia.

Se incluye en la colección, finalmente, un documento que se conserva en el Archivo Vaticano.

Si hiciésemos un balance de la tipología documental derivada de la documentación villabonense, como ya fue señalado en la

\footnotetext{
55 Este es el caso del privilegio de fundación, de 1229, que diera Alfonso IX. MARTín LÓPEZ, M. E. y CAVERO DOMÍNGUEZ, G. Villabuena, doc. 6.
}

publicación, es bastante restringida y en un porcentaje desproporcionado:

9 privilegios y cartas reales

3 litterae de la cancillería pontificia

15 compraventas

\section{2 donaciones}

3 permutas

\section{2 cartas de traspaso}

$Y$ el resto lo constituyen cartas de foro: el 95 $\%$ de la documentación recogida. De ello puede deducirse también que la adquisición de propiedades por parte del monasterio fue compraventa, no por donaciones, y que muchas de ellas se hicieron en el momento próximo a la fundación, realizada por Teresa de Portugal, incluso ya fallecido Alfonso IX, y con el apoyo de las infantas Sancha y Dulce.

Otra de las características del fondo es que muchos documentos originales han desaparecido. Algunos de ellos fueron recuperados, a través de los registros notariales, por las abadesas a lo largo del siglo $\mathrm{XV}$; pero otros se perdieron en tiempos posteriores, cuando el monasterio ya había desaparecido y sus fondos estaban transferidos a San Miguel. Las causas de estas pérdidas se deben, sin duda, a las salidas de la documentación fuera del monasterio para la defensa de los derechos ante tribunales de justicia. Afortunadamente, esta documentación se conservaba en el monasterio cuando el padre Tomás de Peralta, monje de Osera, confeccionaba su inventario de documentos en 1679, libro tumbo ya mencionado. Buena parte de los documentos que realizara el monasterio con sus vasallos $y$ dependientes se han recuperado gracias a esta fuente.

Otra característica, en este caso cronológica, nos da también cierta descompensación: la

56 CAVERO DOMíngUEZ, G. “Nobles y monjes. Los Osorio villafranquinos y los monasterios bercianos (siglos XIV-XV)". Hispania Sacra, 2016, n. 68, pp. 581-591. 
documentación es fundamentalmente detectada en la última etapa de vida monástica; nada menos que el $71,75 \%$ se encuentra entre 1400 y 1527 . Muy pocos documentos son anteriores a la fundación monástica, y de la primera etapa llama la atención un inventario de vasallos, hecho por el monje Juan, probablemente de Carracedo, preparado en 1238, por orden de la propia reina Teresa; este inventario, realizado para la gestión, especifica de forma detallada lo que fue el patrimonio inicial del monasterio de San Guillermo. Su importancia era tal que desapareció del monasterio y actualmente está en el archivo ducal de Medinasidonia. Por ello, resultaba tan difícil a las monjas de San Miguel mantener el patrimonio de Villabuena: se habían quedado sin documentos básicos para su defensa.

Otra particularidad importante es que, dado que la mayor parte de la documentación es de cronología muy tardía, es documentación notarial, realizada por escribanos públicos ${ }^{57}$. Se trata de documentos que siguen utilizando el pergamino, con una escritura profesionalizada (góticas cursivas), que siguen un formulario sistemático propio de los negocios jurídicos. Se utiliza el castellano, pero dada la proximidad con Galicia se detectan frecuentes galleguismos. La colección de Villanueva cuenta con un apéndice en que se registran las "Suscripciones de notarios que intervienen en la documentación" 58 .

\section{Conclusiones}

A modo de conclusión, señalamos que la mayor parte de los archivos monásticos

57 "El monasterio de San Guillermo, al igual que otras instituciones religiosas, carece de scriptorium propio y acude, normalmente a los funcionarios públicos, como el resto de los ciudadanos, para la realización de los negocios jurídicos. Así pues, la documentación muestra una diversidad de escribanos de la zona: las monjas bien acuden a los notarios reales que actúan en las villas cercanas, como Villafranca, de nombramiento señorial, a fueron ordenados en los siglos de época moderna, teniendo como objetivo organizar la documentación con el fin de hacer posible su consulta. La cajonería, por ejemplo, en el caso de Carrizo permitía ordenar por lugares, poniendo numeraciones y títulos. Y ello era posible al sacar las escrituras que estaban enrolladas, en unos casos, y con frecuencia metidas en fardeles; lo que las ponía en difícil y caótica consulta.

Es corriente que la ordenación se haga por personas ajenas a las comunidades, muy frecuentemente del propio entorno cisterciense, dada la presencia de monjes confesores en los monasterios femeninos, que se ocuparon habitualmente de hacer tumbos e historias monásticas. En otras ocasiones la catalogación y ordenamiento era encargado a personas ajenas a la orden, pero cualificadas para la realización de dicha tarea.

Con motivo de la desamortización del siglo XIX varios de los fondos sufrieron distintas vicisitudes: desde una dispersión de los fondos realmente espectacular (como es el caso de Otero de las Dueñas), a una fragmentación que condujo parte de la documentación al Archivo Histórico Nacional y a una simple permanencia en los claustros. Constatamos que los efectos desamortizadores tuvieron menos incidencia en los claustros femeninos que en los masculinos, y de los seis monasterios considerados, sólo dos desaparecieron en ese momento. El tercero, Villabuena, había desaparecido ya en el siglo XVI. Pero la desamortización no fue la única causa de la desintegración de los archivos y de la pérdida de documentos: las monjas confiaron la gestión de su patrimonio a monjes y

notarios públicos de concejo como el de Ponferrada, bien recurren a los escribanos de nombramiento episcopal, como la notaría de Cacabelos, generalmente procedentes de Santiago, o a escribanos del rey que trabajan en el territorio". MARTÍN y CAVERO, Villabuena, p. 53.

58 lbíd., pp. 77-83, en que se registran un total de 41 suscripciones entre 1240 y 1527. 
mayordomos, cuando no la entregaron a encomenderos. Pleitearon por la defensa de sus tierras y propiedades; lo que llevó a que, en varios casos, la documentación saliera del monasterio y no volviera.

De los seis monasterios cistercienses y femeninos conservados, en su mayor parte fundados por reyes y nobles, el de Otero de las Dueñas alberga dos archivos nobiliarios altomedievales de gran trascendencia que recalaron en el monasterio a través de su fundadora, María Núñez de Guzmán, descendiente de los Fróilaz.

Dado que perviven actualmente las comunidades cistercienses en Santa María de Gradefes, San Miguel de las Dueñas y Santa María de Carrizo, en ellos se ubican sus fondos respectivos y los de aquellas comunidades con las que tuvieron relación, 0 a las que simplemente absorbieron.

\section{Bibliografía}

Archivo del monasterio de San Miguel de las Dueñas: Tumbo en que se dará razón de todos los papeles e instrumentos de el archivo de este real monasterio de San Miguel de las Dueñas. Escriviólo y dispúsolo el Padre fray Thomás de Peralta, hijo de Osera y confesor en dicho monasterio.

Archivo del monasterio de San Miguel de las Dueñas: Historia del Real Monasterio de Monjas Cistercienses de la Congregación de N. P. S. Bernardo, de San Miguel de las Dueñas, por el P. Fr. Ambrosio Delgado, monge de la misma orden, confesor cura del dicho monasterio parroquia.

BAURY, Ghislain. "Fundar una abadía cisterciense femenina a mediados del siglo XIII. En torno a los inicios de Otero (12301452)". Estudios Humanísticos. Historia, 2014, n. 13, pp. 9-34.

BURÓN CASTRO, Taurino. Colección documental del monasterio de Gradefes, I (1054-1299), León 1998; y II (1300-1899), León, 2000.
CALVO, Aurelio. El monasterio de Gradefes. Apuntes para su historia y la de algunos otros cenobios y pueblos del concejo. León, 19361944.

CANAL SÁNCHEZ-PAGÍN, José María. "Documentos del monasterio de Carrizo de la Ribera (León) en la Colección Salazar de la Real Academia de la Historia". Archivos Leoneses, 1978 , n. 64, pp. 381-403.

CASADO LOBATO, María Concepción. Colección diplomática del monasterio de Carrizo (León), I: Introducción, documentos de los años 969-1260; II: Documentos de los años 1260-1299 e Índices. León, 1983.

CAVERO DOMÍNGUEZ, Gregoria. Catálogo del monasterio de San Miguel de las Dueñas. León: Universidad de León, 1994.

CAVERO DOMíngUEZ, Gregoria. "Teresa de Portugal, reina de León". En Los Reyes de León, coord. por Adolfo Alonso Ares. León, 1994.

CAVERO DOMÍNGUEZ, Gregoria. "Teresa de Portugal y el monasterio de Villabuena (s. XIII)". Cistercium, 1997, n. 208, pp. 379-388.

CAVERO DOMÍNGUEZ, Gregoria. El esplendor del Císter en León, siglos XII-XIII. León, 2007.

CAVERO DOMÍNGUEZ, Gregoria. "Las condesas Estefanía Ramírez y su hija María Ponce: estrategias familiares femeninas". En Femina. Mujeres en la Historia, coord. por Cristina de la Rosa Cubo et al. Valladolid, 2015, pp. 49-70.

CAVERO DOMínGUEZ, G. "Nobles y monjes. Los Osorio villafranquinos y los monasterios bercianos (siglos XIV-XV)". Hispania Sacra, 2016, n. 68, pp. 581-591.

CAVERO DOMÍNGUEZ, Gregoria y GONZÁLEZ GARCíA, Miguel Ángel. El monasterio cisterciense de San Miguel de las Dueñas. León, 2000.

DA COSTA C. NASCIMENTO, Maria Filomena. "Los Morán: un linaje nobiliario en León (siglo XIII)". Astorica, 1990, n. 9, pp. 75-142; y 1991, n. 10, pp. 11-64. 
FERNÁNDEZ FLÓREZ, José Antonio y HERRERO DE LA FUENTE, Marta. Colección documental del monasterio de Santa María de Otero de las Dueñas (854-1108), I (854-1108) León, 1999; y II (1109-1299) e Índices, León, 2005.

GAUTIER DALCHÉ, J. "Noblesse, terre et argent au XIII siècle: l'exemple de la famille léonaise des Moran". En Histoire et Societé. Mélanges offerts a Georges Duby. Université de Provence, Aix-en-Provence, 1992, pp. 97105.

MARTÍN LÓPEZ, María Encarnación y CAVERO DOMÍNGUEZ, Gregoria. Colección documental del monasterio de San Guillermo de Villabuena (1172-1527). León: Universidad de León, 2017.

PÉREZ ÁLVAREZ, María José. "Presencia y desarrollo del dominio monacal de las monjas bernardas de Avilés en el Valle de Laciana". En Claustros Leoneses olvidados. Aportaciones al monacato femenino. León, 1996.
PRIETO PRIETO, A. "Documentos referentes al orden judicial del monasterio de Otero de las Dueñas". Anuario de Historia del Derecho Español, 1974, n. 44, pp. 619-674

RODRÍGUEZ, Raimundo. Catálogo de documentos del monasterio de Santa María de Otero de las Dueñas. León, 1949.

RUIZ ASENCIO, José Manuel. Colección documental de la Catedral de León, VIII (12301269). León, 1993.

YÁÑEZ NEIRA, Damián. "El monasterio cisterciense de las Huelgas de Avilés". Boletín del Instituto de Estudios Asturianos, 1969, n. 68, pp. 341-372.

YÁÑEZ NEIRA, Damián. "El monasterio de Villabuena, fundación de una santa reina". Archivos Leoneses, 1986, n. 40, pp. 79-80. 